\title{
Historical and Current Conditions Including COVID-19 Requiring Anti-Pathogenic Surveillance and Proper Immunogenic Support
}

Leonard Sonnenschein ${ }^{1 *}$, Robert Weinberg ${ }^{2}$, H Thomas Cotter ${ }^{3}$, Lawrence A Salvo ${ }^{4}$, Tiberious Etyang $^{5}$, Kevin Paul Bethel ${ }^{6}$ and Ruth E Frischer ${ }^{7}$

${ }^{1}$ Conservation for the Oceans Foundation, Salvation Farming Solutions, USA

${ }^{2}$ First Boca Associates, Business Strategist \& Advisors Boca Raton, USA

${ }^{3}$ The American Homeopath, USA

${ }^{4}$ Consortium International Holdings, USA

${ }^{5}$ Managing Director, Salvation Farming Solutions, Kenya

${ }^{6}$ Integrative Medicine Consultant, Family Wellness Centre, Bahamas

${ }^{7}$ Chief Health Scientist, Frischer-Dambra Consulting, USA

*Corresponding author: Leonard Sonnenschein, Conservation for the Oceans Foundation and Founder /Chief Science Officer/ Chairman -Salvation Farming Solutions, LLC, 9858 Clint Moore Rd., STE C111-177 Boca Raton, FL 33496, USA

To Cite This Article: Sonnenschein L, Weinberg R, Cotter HT, Salvo LA, Etyang T, Bethel KP, Frischer RE, et al., Historical and Current Conditions Including COVID-19 Requiring Anti-Pathogenic Surveillance and Proper Immunogenic Support. 2020 - 8(4). AJBSR.MS.ID.001292. DOI: 10.34297/AJBSR.2020.08.001292.

Received: 鮆 April 10,2020; Published: 眥 April 15, 2020

\begin{abstract}
Everyone on the planet will eventually be exposed to COVID-19. The question of who will get ill, who will die and who will survive will depend more on appropriate preparations than on a vaccine. In addition, this current pandemic threat may pose a harbinger of what is yet to come. The key is to strengthen our immunological support and surveillance. In this way, we will have greater capacity to address future variant viral strains. This brief communication explores some of the historical, societal and economic sequelae resulting from pandemics. It will also embark upon some promising stabilizing treatments.
\end{abstract}

Keywords: Effective COVID-19 Solution, COVID-19, Virus, IgG, IgM, Alternative Treatments, Health Hydration drink, Antimicrobial Solution, Pandemic Solution, Pandemic History, African Farming Threats, Third World Pandemic Effects.

\section{Introduction}

Everyone on the planet will eventually be exposed to COVID-19. The question of who will get ill, who will die and who will survive will depend more on appropriate preparations than on a vaccine. In addition, this current pandemic threat may pose a harbinger of what is yet to come. The key is to strengthen our immunological support and surveillance. In this way, we will have greater capacity to address future variant viral strains. This brief communication explores some of the historical, societal and economic sequelae resulting from pandemics. It will also embark upon some promising stabilizing treatments.

\section{How the Process Manifests}

The virulence of the virus (in its devastating processes) disengages the normal inflammatory response and obfuscates appropriate actions and reactions of the body, resulting in secondary infectious processes. These would normally assist the resultant pathology. Exasperating this is the fact that we are not dealing with a bacteria, protozoa, fungus, algae or yeast that normally would respond to medical interventions. With a virus one needs to plan on how to lower the inflammation curve, resulting in a more normalized response. 
More details on the development of the COVID-19 disease epidemiology

The incubation timeline (Figure 1), following point of infection, is up to 14 days after point of first contact. The first immunological consequence to develop and which can be identified is the IgM Antibody. IgM has a short-term presence in the blood which comes on immediately following incubation reaching its peak after approximately 9-11 days. The patient can be symptomatic or asymptomatic. From day 7, following the incubation of the disease, the IgG begins to rise and IgM begins to fall off. For a while, both IgG and IgM are present in the blood until about day 31 when the IgM falls off completely leaving only the IgG which then also continues to drop. However, during this time, the possibility of reinfection can occur and likewise this process does not protect from significantly novel new pathogens. The cascade of exposures world-wide and the length of time necessary to develop immune competency means that conservatively we will be dealing with the COVID-19 sequence of infections for at least several more months. However, new strains may develop that may significantly lengthen the development of immunity or until there is a vaccine that could adequately cover the expanse of disease possibilities. This understanding of COVID-19 is still evolving.

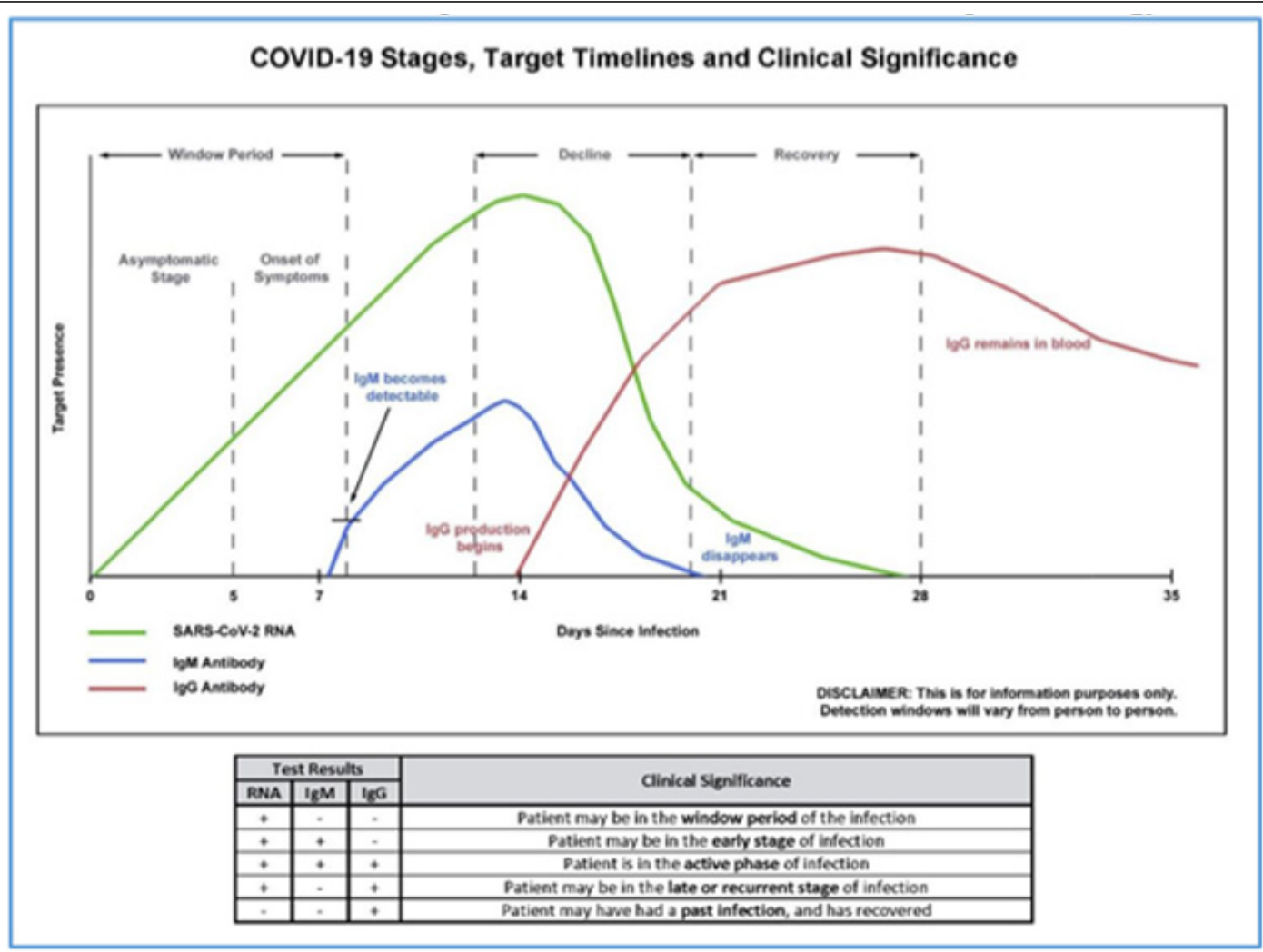

Figure 1: Courtesy of Consortium International Holdings, LLC.

\section{Some alternative treatments}

With the evolution of the COVID-19 onslaught and the unavailability of $100 \%$ effective and safe treatments, many avenues of therapy have evolved. There are traditional therapies that are well referenced in PubMed that are very effective. These Health Strategies include:

Strategy 1: Modulate Innate Immune System. Vitamin D3 5000 iu(international units) daily as prevention $2 \mathrm{x}$ day as therapy.

Strategy 1b: To Avoid Immune Suppression??? or over Stimulation???

Strategy 2: Inhibit Virus Access to Cell Receptor ACE-2 Complex. Pycnogenol $25 \mathrm{mg}$ daily as prevention and 3xday as therapy.
Strategy 2b: Mitigate ACE2 Promoters. Estrogen and Uric Acid.

Strategy 3: Inhibit Serine Protease function of promoting virus RNA entry into the cell. Papaya, Green Tea EGCG, Bowman Birk Peanut Skins, Neem Tree/oil.

Strategy 3b: Avoiding Serine Protease PROMOTERS. Phenobarbital, 16- alpha Ethinylestradiol in BCP.

Strategy 4: Inhibit RNA Polymerase "Viral Replicase enzyme". ZINC 25mg daily for prevention and 2-3xday for treatment.

Strategy 4b: Avoid RNA polymerase promoters. Vitamin B3

Strategy 5: Add a Zinc ionophore to increase zinc concentration in the infected cell. Quinine 300mg 1-3xday, Hydroxychloroquine 200mg 1-3xday, Must be taken with Zinc. 
Strategy 5b: Avoid Zinc Chelators in the diet. Oysters and Sea Cucumber.

Strategy 6: Down regulate Furin Cytokine Cascade. Alpha Lipoic Acid 100-500mg 1-3x day based on clinical evaluation.

Strategy 6b: Down Regulate virus related Free Haemoglobin. Ascorbic Acid Vitamin C 1000-2000mg 1-3 times a day.

Strategy 7: Inhibit Virus Release from the Infected Cells. Lauric Acid (MCT) Coconut and oil.

\section{Historical Understandings}

Professor Benjamin Franklin Buchanan was struck down by the great flu pandemic (1917 to 1920). It was a horrible ordeal then and even worse than what we have yet experienced. The current danger is: Will the next waves of pathogens be short and what about places such as in the developing economies such as African Continent where there's not quite as much medical assistance possible lead-in to even greater death tolls? The timing of COVID-19 outbreak came when most of the countries in Africa and Asia were dealing with the devastation of desert locusts that has destroyed crops and thus exposing the population to food insecurity. Coronavirus pandemic is hampering efforts to contain the growing swarms of desert locusts in the continent. As of April 2020, more than 25million hectares of farmland are affected in Ethiopia, Kenya and Somalia; hardest hit countries and the COVID-19 have restricted air travel and other efforts in tackling the locusts menace. The same situation is being experienced in Yemen and Saudi Arabia where new swarms are reported. These countries are all facing food shortages and threatened livelihoods with starvation and disease likely results of this survival combination creating a new normal.

In retrospect, the early 80s a new disease (AIDS) was discovered and called "slims." Many celebrities had been struck with this disease. It manifested with lose of much body weight with death usually from Kaposi sarcoma. Since sarcoma was cancer of the small lining of the glandular system, it was assumed it was a contagious form of cancer (as I started learning about "slims"). Fortunately for man, the AIDS virus cannot live in an oxygen environment. And that probably saved our species from extinction by AIDS. As it turns out the genetics of COVID-19 also has links to several other usually virulent viruses.

The pandemic nature of what COVID-19 is causing certainly will have long-lasting effects on peoples' health and well-being and history will likely reveal many other shocking realities that we are living through now.

\section{Economic and Social realities of current COVID-19 Pan-} demic

The world as we knew it stopped a few weeks ago, now to a new profound reality. The impact of COVID-19 virus is historically unprecedented. Since there has been no approved pharmaceutical treatment to arrest the spread of this infection, the treatment of political choice has resulted in a devastating and unsustainable cessation of commerce and social interaction.

The cost and reversibility of this socio-economic disaster aggregates each day that an effective medical treatment is not deployed. The evaluation of existing safe and effective, broad spectrum treatments for pathogens, including viruses must be an international PRIORITY.

In addition to the benefits offered by the natural supplements discussed, there is an imperative need to have an overarching safe and effective solution based on immunological and global surveillance network. This Solution should have a profound and immediate impact on both the medical and social-economic aspects of the current crises.

\section{Current Solution}

A high profile, $3^{\text {rd }}$ party validated, non-prescription solution is currently being developed that will be available as a health hydration liquid. It will be cost-effective, readily available and enable swift global availability to help contain and halt pathogen vectors where and when they occur.

The Solution is $99.9 \%$ spring water with about one tenth of one percent mineral content. Recommended drink size is $1 \mathrm{oz}$, one time, or may be used multiple times with no toxicity. The minerals are well known and should be determined "safe" (GRAS- Generally Recognized As Safe) to initially market as a "health support" drink (with no claims).

Solution samples and support information are available for evaluation. Recommendations of channels and resources to accelerate this process will have critical lifesaving and economic implications.

If a widely available, inexpensive, non-prescription product, with only beneficial side effects, was able to stop and eliminate the disease at its earliest stages; there should immediately be no further need for an economic and social lock down.

The COVID-19 virus would then be less threatening than the common cold for which we have had no cure (at least until now). At first signs of symptoms or exposure the product could be shipped overnight or sold at any convenience, grocery or drug store.

\section{What is next: Conclusion and Recommendations}

New protections and precautions must be put in place such as placing long anti- microbial product on face masks and other PPE, appropriately sanitizing and protection of living spaces: walls, ceilings, floors, HVACs, ATMs and seating to name a few. There are new products that can provide disinfection for up to one-year. 
We need to promote wide-scale use of products that everyone can use such as health drinks, vitamins, immune support nutritional supplements, and be more surveillant of the spaces we live in and our habits to better respond to the existent threat of extreme pathogens. 